\title{
FIRST RECORD OF THE ORIBATID MITE GENUS EPIDAMAEUS (ACARI, ORIBATIDA, DAMAEIDAE) FROM TAIWAN
}

\author{
Sergey G. Ermilov ${ }^{*}$, Jhih-Rong Liao ${ }^{2}$ and Alexey A. Gubin ${ }^{1}$
}

\author{
${ }^{1} \mathrm{X}$-BIO Institute, Tyumen State University, Tyumen, Russia \\ ${ }^{2}$ National Taiwan University, Taipei, Taiwan \\ *corresponding author; e-mail: ermilovacari@yandex.ru
}

\begin{abstract}
This article presents the first record of the oribatid mite genus Epidamaeus (Oribatida, Damaeidae) in Taiwan. A new species, Epidamaeus saviah Ermilov sp.n., is described based on the material recovered from the soil and lichens collected in Yushan National Park (Taiwan). The newly discovered species differs from Epidamaeus barbatulus (Choi, 2004) in the length and the morphology of parastigmatic apophyses and notogastral setae, as well as in the absence of ventrosejugal tubercles.
\end{abstract}

KEY WORDS: Damaeid mites, systematics, morphology, Oriental region

DOI: 10.21684/0132-8077-2020-28-2-115-122

\section{INTRODUCTION}

This work, based on oribatid mite material collected in Yushan National Park, is part of our ongoing study of oribatid mites (Acari, Oribatida) of Taiwan (e.g., Ermilov and Liao 2017, 2018, 2019). During the taxonomic identification, we have discovered one new species belonging to Epidamaeus Bulanova-Zachvatkina, 1957 (family Damaeidae). It is the first record of this genus in Taiwan. The main goal of this paper is to describe and illustrate this species, which received the name Epidamaeus saviah sp.n.

Epidamaeus was proposed by BulanovaZachvatkina (1957) with Oribata bituberculata Kulczynski, 1902 as type species. At present, the genus comprises about 80 species, distributed in the Holarctic, Neotropical and Oriental regions. Epidamaeus's generic traits were summarized by Bulanova-Zachvatkina (1957, 1975) and Miko (2006). The identification keys to some species of Epidamaeus were presented by Bulanova-Zachvatkina (1975), Miko (2006) and Bayartogtokh (2010).

\section{MATERIALS AND METHODS}

Locality. Substrate samples containing oribatid mites were collected in Yushan National Park in 2018. The Park is located in the central part of Taiwan $\left(23^{\circ} 28^{\prime} \mathrm{N}, 120^{\circ} 57^{\prime} \mathrm{E}\right)$ and covers about 103,121 ha. Numerous canyons, cliffs and valleys that contribute to the Park's impressive 3,600 m elevation range, create perfect conditions for high levels of biodiversity.

Specimens. Mites were extracted into $75 \%$ ethanol using Berlese's funnels with electric lamps in laboratory conditions in the course of 10 days.

Specimens are distributed among two institutions: the National Taiwan University, Taipei,
Taiwan (NTU) and the Tyumen State University Museum of Zoology, Tyumen, Russia (TSUMZ).

Observation and documentation. Specimens were mounted in lactic acid on temporary cavity slides for measurement and illustration. Body length was measured in lateral view, from the tip of the rostrum to the posterior edge of the notogaster. Notogastral width refers to the maximum width of the notogaster in dorsal view. Lengths of body setae were measured in lateral aspect. All body measurements are presented in micrometers $(\mu \mathrm{m})$. Formulas for leg setation are provided in parentheses, according to the sequence trochanter-femurgenu-tibia-tarsus (famulus included). Formulas for leg solenidia are provided in square brackets according to the sequence genu-tibia-tarsus.

Drawings were made with a camera lucida using the "Leica DM 2500" transmission light microscope. SEM micrographs were taken with the aid of a JEOL-JSM-6510LV SEM microscope.

Terminology. The morphological terminology used in this paper follows mostly that of F. Grandjean: see Travé and Vachon (1975) for general references; Miko and Mourek (2008), Miko (2010, 2015), Norton (1977) for leg setal nomenclature; and Norton and Behan-Pelletier (2009) for overview.

Abbreviations. Prodorsum: $a b r$ - anterobothridial ridge; $f$-furrow; $b r$-basal ridge; $P$ - propodolateral apophysis; $r o$, le, in, $b s$, ex-rostral, lamellar, interlamellar, bothridial, and exobothridial setae, respectively; $B a$-prodorsobasal tubercle; bo-bothridium. Notogaster: $c, l a, l m, l p, h, p-$ notogastral setae; $s a$-spina adnata; $i a, i m, i p, i h$, ips-notogastral lyrifissures; gla-opisthonotal gland opening. Gnathosoma: $a, m, h$-subcapitular setae; or-adoral seta; $d, l, v, c m, a c m, u l, s u, v t$, 
lt — palp setae; $\omega$ - palp and leg solenidion; cha, $c h b$-cheliceral setae; $T g$ - Trägårdh's organ. Epimeral and lateral podosomal regions: $1 a, 1 b$, 1c, $2 a, 3 a, 3 b, 3 c, 4 a, 4 b, 4 c, 4 d$-epimeral setae; $S a, S p$-parastigmatic tubercles; dis-discidium. Anogenital region: $g$, ag, an, ad-genital, aggenital, anal and adanal setae, respectively; iad-adanal lyrifissure; po - preanal organ. Legs: $\mathrm{Tr}, \mathrm{Fe}$, $\mathrm{Ge}, \mathrm{Ti}, \mathrm{Ta}$ - leg trochanter, femur, genu, tibia, tarsus, respectively; $p a$-porose area; $\omega, \varphi, \sigma$-leg solenidia; $\varepsilon$ - leg famulus; $d, l, v, b v, e v, f t, t c, i t$, $p, u, a, s, p v, p l$-leg setae.

\section{SYSTEMATICS}

\section{Superfamily Damaeoidea \\ Family Damaeidae \\ Genus Epidamaeus Bulanova-Zachvatkina, 1957}

Type species Oribata bituberculata

Kulczynski, 1902

\section{Epidamaeus saviah Ermilov, sp. $n$.}

Figs. 1-15

Diagnosis. Body size: 415-498 × 249-315. Body with tuberculate cerotegument. One pair of prodorsobasal tubercles $(B a)$ developed, elongate triangular. Rostral and lamellar setae long, setiform, ro barbed, le shortly ciliate. Interlamellar seta of medium length, setiform, slightly barbed, straight, directed posteriad. Bothridial seta very long, flagellate, barbed. Spina adnata comparatively short, elongate triangular. Notogastral setae $c, l a, l m, l p, h, p_{1}$ long, setiform, semicircularly curved, heavily barbed, setae $p_{2}, p_{3}$ short, setiform, thin, slightly barbed. Parastigmatic apophyses $S a$ and $S p$ elongate thorn-like, distally located parallel and close to each other, $S a$ distinctly shorter than $S p$. Epimeral and ventrosejugal tubercles absent. Epimeral and anogenital setae setiform, slightly barbed. Epimeral setal formula: 3-1-3-4. Discidium triangular. Formulas of leg segments (I-IV): femur 7-6-4-4; genu and tibia 4-4-3-3; tarsus 20-17-17-14.

Description. Measurements. Body length: 431 (holotype, male), 415-498 (nine paratypes, six males and three females); notogaster width: 265 (holotype), 249-315 (nine paratypes). Females larger than males: $448-498 \times 282-315$ vs. $415-$ $431 \times 249-265$.

Integument (Figs. 10-15). Body color brown. Surface of body and legs with slight and dense microsculpturing (rounded and elongate tubercles and ridges), covered by a thick layer of gel-like cerotegument (with numerous tubercles (diameter up to 4) and bacillar structures). Sejugal, epimeral and lateral podosomal regions sometimes with filamentous cerotegument.

Prodorsum (Figs. 1, 3, 10, 12-14). Rostrum rounded. Median part with two slight transverse furrows (one anterior to lamellar setae, the other anterior to interlamellar setae). Anterobothridial ridge present. Propodolateral apophysis developed, strong, elongate tubercle-like. One pair of prodorsobasal tubercles $(B a)$ developed, triangular. Basal part of prodorsum with long transverse ridge. Rostral seta (65-73) setiform, barbed. Lamellar seta (77-86) setiform, shortly ciliate. Interlamellar seta (36-41) setiform, slightly barbed, straight, directed posteriad. Exobothridial seta (36-41) setiform, barbed. Bothridial seta (225-237) flagellate, barbed.

Notogaster (Figs. 1, 3, 10, 12-14). Oval. Exuvial scalps absent. Spina adnata (24-26) elongate triangular, slightly curved, pressed to the surface of notogaster. Dorsal notogastral setae of dark color, setiform, semicircularly curved, heavily ciliate, $l a, l m, l p, h_{3}(86-94)$ longer than $c_{1}, c_{2}, h_{1}$, $h_{2}(61-73)$ and $p_{1}(36-45)$. Posterior setae $p_{2}, p_{3}$ (20-28) of light color, setiform, thin, slightly barbed. Opisthonotal gland opening, all notogastral lyrifissures and circumgastric scissure distinct. Circumgastric sigillar band not observed.

Gnathosoma (Figs. 2, 4, 5, 11). Subcapitulum size: 94-106× 77-86. Subcapitular setae ( $a, 16-20$; $m$ and $h, 32-36)$ setiform, slightly barbed. Adoral seta (8-10) setiform, roughened. Palp (77-82) with typical formula: $0-2-1-3-9(+\omega)$. Postpalpal seta (4) spiniform. Chelicera (94-106) with two setiform setae, cha (20-24) barbed, chb (12-16) unilaterally ciliate in mediodistal part.

Epimeral and lateral podosomal regions (Figs. $2,3,11,12$ ). Epimere I without clear median concavity. Parastigmatic apophyses $S a$ and $S p$ elongate thorn-like, distally located parallel and close to each other, $S a$ distinctly shorter than $S p$. Epimeral and ventrosejugal tubercles absent. Epimeral setal formula: 3-1-3-4. All setae setiform, barbed; $1 a$, $1 c, 2 a, 3 a, 4 a, 4 b$ (16-24) shorter than $1 b, 3 b, 3 c$, $4 c, 4 d$ (36-45). Discidium triangular, blunt.

Anogenital region (Figs. 2, 3, 11, 12). Six pairs of genital, one pair of aggenital, two pairs of anal and three pairs of adanal setae similar in length (16-20), setiform, slightly barbed. Adanal lyrifissure diagonal, located close to anal plates and anteriorly to adanal seta $a d_{3}$. 


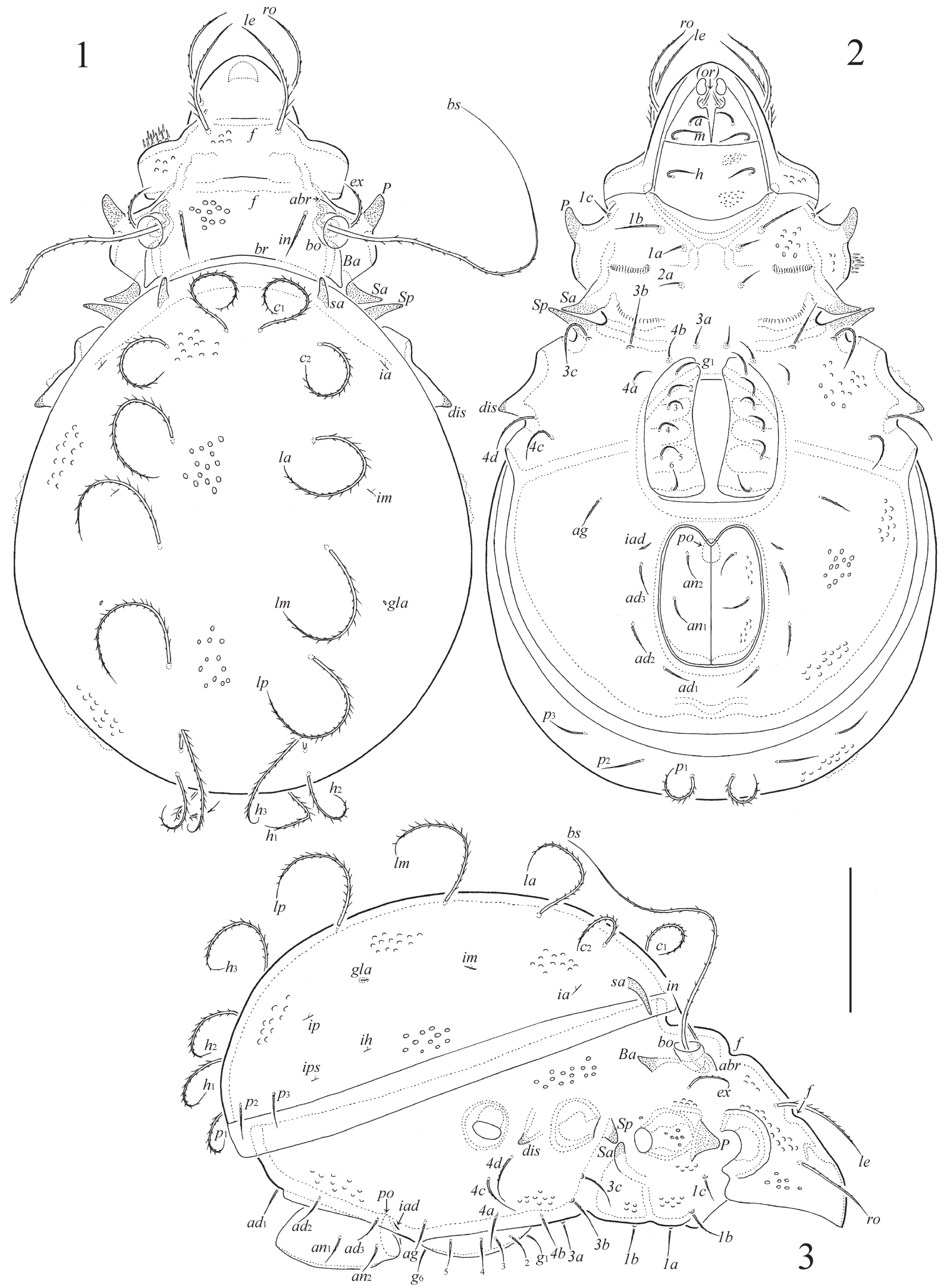

Figs. 1-3. Epidamaeus saviah Ermilov sp.n., adult: 1-dorsal view (not shown: legs); 2-ventral view (not shown: legs); 3 -lateral view (not shown: gnathosoma and legs). Scale bar $=100 \mu \mathrm{m}$. 


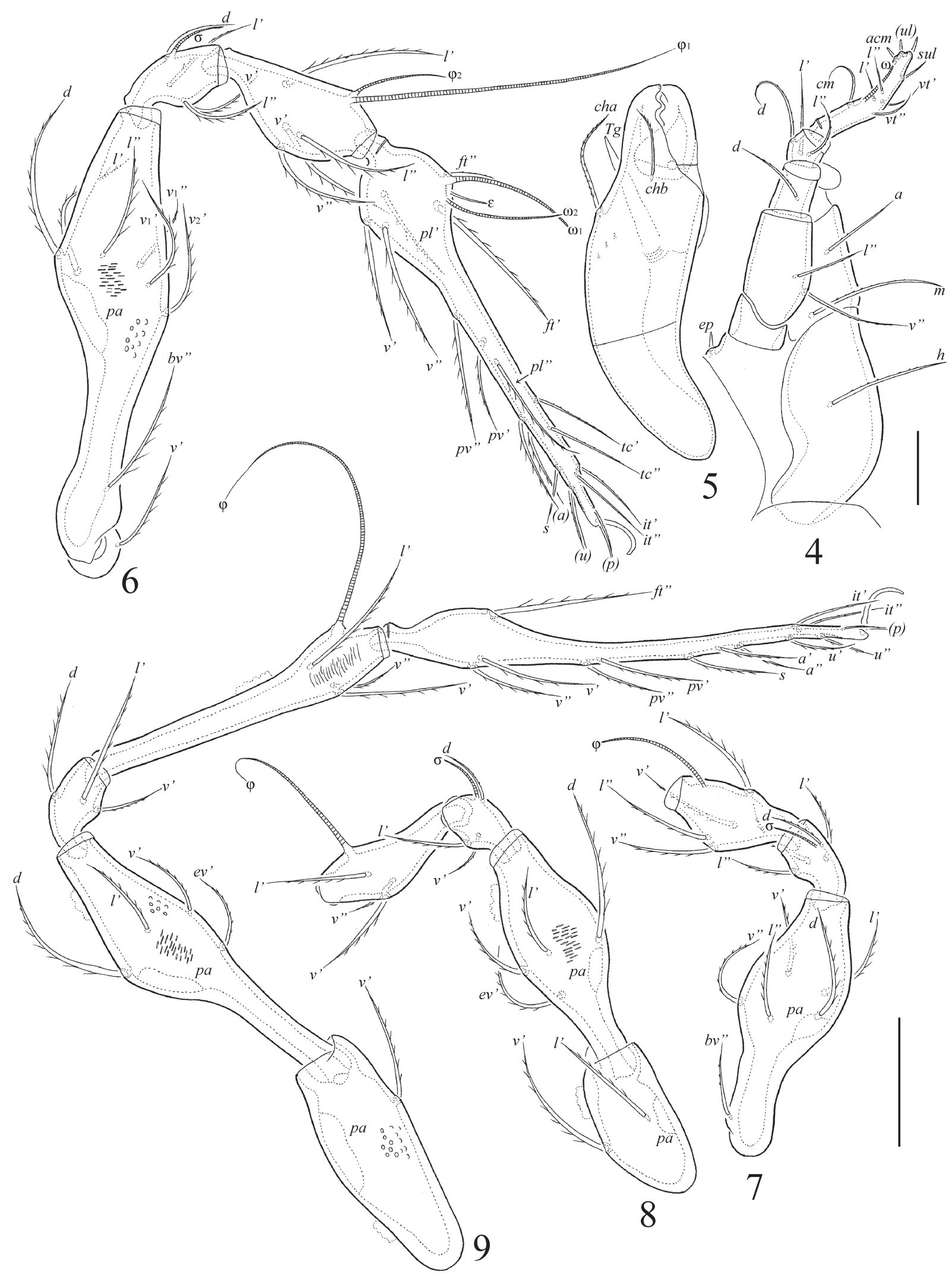

Figs. 4-9. Epidamaeus saviah Ermilov sp.n., adult: 4—-subcapitulum and right palp, lateral view; 5-chelicera, right, antiaxial view; 6-leg I, right, antiaxial view; 7-leg II, without trochanter and tarsus, left, antiaxial view; 8-leg III, without tarsus, right, antiaxial view; 9-leg IV, left, antiaxial view. Scale bars=20 $\mu \mathrm{m}(4,5), 50 \mu \mathrm{m}(6-9)$. 

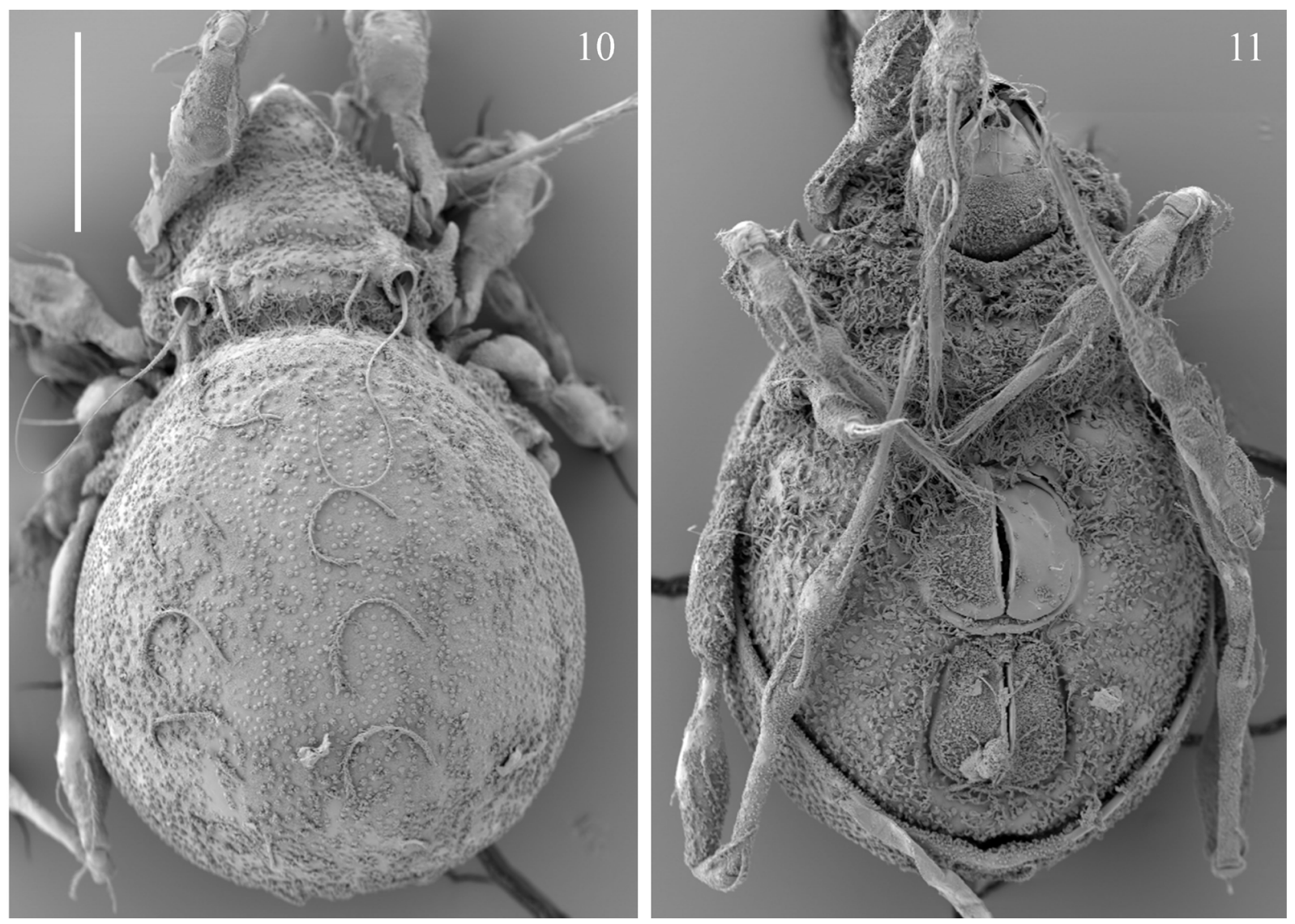

Figs. 10-11. Epidamaeus saviah Ermilov sp.n., adult, SEM micrographs: 10—dorsal view; 11-ventral view. Scale bar $=200 \mu \mathrm{m}$.

Legs (Figs. 6-9, 12). Leg I similar to body in length, legs II and III shorter than body length, leg IV longer than body length, approximately (Table 1). Claw comparatively small, thin, smooth. Porose area on femora I-IV and on trochanters III and IV distinctly visible. Formulas of leg setation and solenidia: I (1-7-4-4-20) [1-2-2], II (1-6-4-417) $[1-1-2]$, III (2-4-3-3-17) [1-1-0], IV (1-43-3-14) [0-1-0]; homologies of setae and solenidia indicated in Table 2. Solenidion on genua I-III slightly shorter than coupled setae $d$. Famulus of tarsus I short, setiform, inserted between solenidia $\omega_{1}$ and $\omega_{2}$. Thick seta on all segments absent. Many setae shortly ciliate. Seta $v_{2}$ absent on all tarsi.

Material examined. Holotype (male) and five paratypes (four males and one female): Taiwan, Nantou County, Xinyi Township, Guanfeng, Yushan National Park, mountainous area, $23^{\circ} 32.483^{\prime} \mathrm{N}, 120^{\circ} 54.483^{\prime} \mathrm{E}, 1,547 \mathrm{~m}$ a.s.1., soil, 14.IX.2018 (J.R. Liao and H.C. Lee). Four paratypes (two males and two females): Taiwan, Nantou County, Xinyi Township, Yushan National Park, Tataja Anbu trail entrance, tall mountain, $23^{\circ} 28.533^{\prime} \mathrm{N}, 120^{\circ} 54.000^{\prime} \mathrm{E}, 2,608 \mathrm{~m}$ a. s. 1 , lichen, 28.XII.2018 (J.R. Liao and H.C. Lee).
Type deposition. The holotype is deposited in the NTU; nine paratypes are deposited in the TSUMZ. All specimens are preserved in ethanol with a drop of glycerol.

Etymology. The specific name saviah refers to "Saviah", which is the Bunun language name for the Yushan Mountain. Bunun are the indigenous people who live in the type locality.

Remarks. Epidamaeus saviah Ermilov sp.n. is morphologically most similar to Epidamaeus barbatulus (Choi, 2004) from Korea (see Choi 2004) in the presence of the following features: flagellate bothridial seta, prodorsobasal tubercle $B a$, strong propodolateral apophysis, and heavily ciliate dorsal notogastral setae. However, the new species differs from $E$. barbatulus in the length and the morphology of parastigmatic apophyses $(\mathrm{Sa}$ distinctly shorter than $S p$, both thorn-like vs. $S a$ longer than $S p$, both elongate tubercle-like), the length and the morphology of notogastral setae (setae $c, l a, l m, l p$ comparatively long, semicircularly curved, $p_{1}$ heavily ciliate vs. $c, l a, l m, l p$ of medium length, straight or slightly curved, $p_{1}$ not heavily ciliate) and the absence of a pair of ventrosejugal tubercles (vs. present). 

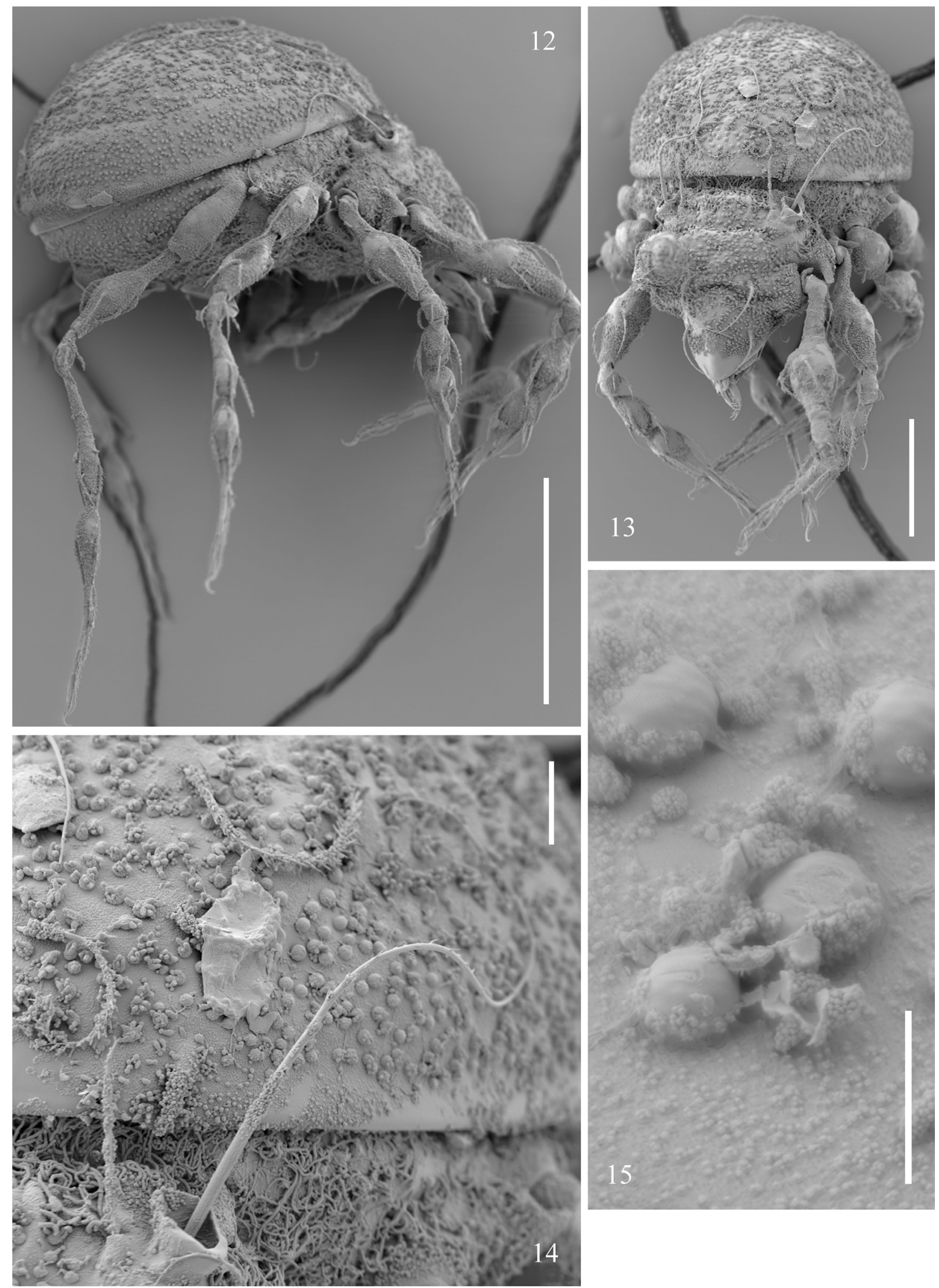

Figs. 12-15. Epidamaeus saviah Ermilov sp.n., adult, SEM micrographs: 12-lateral view; 13-dorsoanterior view; 14 - bothridium, interlamellar and bothridial setae, notogastral setae $c_{1}$ and $c_{2}$, dorsoanterior view; 15-notogastral cerotegumental tubercles and granules. Scale bars $=200 \mu \mathrm{m}$ (12), $100 \mu \mathrm{m}$ (13), $20 \mu \mathrm{m}$ (14), $5 \mu \mathrm{m}$ (15). 


\section{ACKNOWLEDGEMENTS}

We thank C.C. Ko (National Taiwan University, Taipei, Taiwan) for supporting the present study; H.C. Lee for helping with the collection; Yushan National Park for granting permission to carry out our research. This study was funded by the Russian Foundation for Basic Research (RFBR), project № 18-04-00097.

\section{REFERENCES}

Bayartogtokh, B. 2010. Pantsirnye Kleshchi Mongolii (Acari: Oribatida) [Oribatid Mites of Mongolia (Acari: Oribatida)]. KMK, Moscow, 372 pp. [In Russian]

Bulanova-Zachvatkina, E.M. 1957. Epidamaeus grandjeani Bul.-Zachv., gen. et sp.n.- - new oribatid mite from Kuril Islands (Acariformes, Oribatei). Entomologicheskoe Obozrenie, 36(2): 247-552.

Bulanova-Zachvatkina, E.M. 1975. Superfamily Belboidea. In: M.S. Ghilyarov (Ed.). Key to Soil Inhabiting Mites. Sarcoptiformes. Nauka, Moscow, pp. 120-143.

Choi, S. S. 2004. A new species of damaeid mites (Acari: Oribatida) from Korea. Journal of AsiaPacific Entomology, 7(3): 277-281.

Ermilov, S.G. and Liao, J.-R. 2017. New faunistic and taxonomic data on oribatid mites (Acari, Oribatida) of Taiwan. Systematic and Applied Acarology, 22(6): 824-840.

Ermilov, S.G. and Liao, J.-R. 2018. To the knowledge of oribatid mites of the genus Nothrus (Acari, Oribatida, Nothridae) from Taiwan. Biologia, 73(5): 513-521.

Ermilov, S.G. and Liao, J.-R. 2019. Neotype designation and redescription of Dometorina taiwanica
Tseng 1984 and Zygoribatula gratiosa Tseng 1984 (Acari, Oribatida, Oripodoidea). Zoologichesky Zhurnal, 98(4): 377-386.

Miko, L. 2006. Damaeoidea Berlese, 1896. In: G. Weigmann (Ed.). Hornmilben (Oribatida). Die Tierwelt Deutschlands. Teil. 76. Keltern, Goecke and Evers, pp. 179-207.

Miko, L. 2010. Taxonomy of European Damaeidae (Acari: Oribatida) III. Species of the Kunstidamaeus tenuipes (Michael, 1885) group, with a description of Kunstidamaeus fraterculus $\mathrm{n}$. sp. from East Slovakia. Zootaxa, 2327: 51-64.

Miko, L. 2015. Taxonomy of European Damaeidae VIII. Contribution to classification of genus Damaeus C.L. Koch, 1835, with a review of Adamaeus Norton, 1978 and Paradamaeus Bulanova-Zachvatkina, 1957 and redescription of three species. Zootaxa, 3980(2): 151-188.

Miko, L. and Mourek, J. 2008. Taxonomy of European Damaeidae (Acari: Oribatida) I. Kunstidamaeus Miko, 2006 with comments on Damaeus sensu lato. Zootaxa, 1820: 1-26.

Norton, R.A. 1977. A review of F. Grandjean's system of leg chaetotaxy in the Oribatei (Acari) and its application to the family Damaeidae. In: D.L. Dindal (Ed.). Biology of Oribatid Mites. SUNY College of Environmental Science and Forestry, Syracuse, pp. 33-61.

Norton, R.A. and Behan-Pelletier, V.M. 2009. Oribatida. In: G. W. Krantz and D.E. Walter (Eds.). A Manual of Acarology (TX). Texas University Press, Lubbock, Chapter 15, pp. 430-564.

Travé, J. and Vachon, M. 1975. François Grandjean. 1882-1975 (Notice biographique et bibliographique). Acarologia, 17(1): 1-19.

Table 1

Leg mean lengths $(\mu \mathrm{m})$ and their ratio to the body mean length of one paratype Epidamaeus saviah sp.n.

\begin{tabular}{|l|l|l|l|l|l|l|l|}
\hline Leg & Tr & $F e$ & $G e$ & $T i$ & $T a$ & All & Leg: body mean length \\
\hline I & 16 & 143 & 28 & 57 & 147 & 391 & 0.98 \\
\hline II & 16 & 94 & 24 & 45 & 106 & 285 & 0.71 \\
\hline III & 57 & 73 & 20 & 61 & 143 & 354 & 0.88 \\
\hline IV & 77 & 106 & 28 & 110 & 172 & 493 & 1.23 \\
\hline
\end{tabular}


Table 2

Leg setation and solenidia of Epidamaeus saviah Ermilov sp.n.

\begin{tabular}{|l|l|l|l|l|l|}
\hline Leg & $T r$ & $F e$ & $G e$ & $T i$ & $T a$ \\
\hline I & $v^{\prime}$ & $d,(l), b v^{\prime \prime},(v), v_{2}^{\prime}$ & $(l), v^{\prime}, d \sigma$ & $(l),(v), \varphi_{1}, \varphi_{2}$ & $(f t),(t c),(i t),(p),(u),(a), s,(p v),(p l),(v), \varepsilon, \omega_{1}, \omega_{2}$ \\
\hline II & $v^{\prime}$ & $d,(l), b v^{\prime},(v)$ & $(l), v^{\prime}, d \sigma$ & $(l),(v), \varphi$ & $(f t),(t c),(i t),(p),(u),(a), s,(p v),(v), \omega_{1}, \omega_{2}$ \\
\hline III & $l^{\prime}, v^{\prime}$ & $d, l^{\prime}, e v^{\prime}, v^{\prime}$ & $l^{\prime}, v^{\prime}, d \sigma$ & $l^{\prime},(v), \varphi$ & $(f t),(t c),(i t),(p),(u),(a), s,(p v),(v)$ \\
\hline IV & $v^{\prime}$ & $d, l^{\prime}, e v^{\prime}, v^{\prime}$ & $d, l^{\prime}, v^{\prime}$ & $l^{\prime},(v), \varphi$ & $f t t^{\prime},(t c),(p),(u),(a), s,(p v),(v)$ \\
\hline
\end{tabular}

Note: Roman letters refer to normal setae, Greek letters - to solenidia (except $\varepsilon$ - famulus), $d \sigma$ - to seta coupled with solenidion. Single prime (') marks setae on the anterior and double prime (")- - setae on the posterior side of a given leg segment. Parentheses refer to a pair of setae. 